\title{
Collapsin Response Mediator Protein 4a (CRMP4a) Is Upregulated in Motoneurons of Mutant SOD1 Mice and Can Trigger Motoneuron Axonal Degeneration and Cell Death
}

\author{
Laure Duplan, ${ }^{1,2}$ Nathalie Bernard, ${ }^{1,2}$ Wilfrid Casseron, ${ }^{2,3}$ Keith Dudley, ${ }^{1,2}$ Eric Thouvenot, ${ }^{4}$ Jérôme Honnorat, ${ }^{5}$ \\ Véronique Rogemond, ${ }^{5}$ Béatrice De Bovis, ${ }^{6}$ Patrick Aebischer, ${ }^{7}$ Philippe Marin, ${ }^{4}$ Cédric Raoul, ${ }^{1,2}$ \\ Christopher E. Henderson, ${ }^{8}$ and Brigitte Pettmann ${ }^{1,2}$ \\ ${ }^{1}$ Inserm-Avenir Team, Mediterranean Institute of Neurobiology, Inmed, 13273 Marseille, France, ${ }^{2}$ Aix-Marseille Université, Faculté des Sciences, 13288 \\ Marseille, France, ${ }^{3}$ Service des Pathologies Musculaires, Centre de Référence Maladies du Motoneurone, Centre Hospitalier Universitaire Timone, 13005 \\ Marseille, France, ${ }^{4}$ Institut de Génomique Fonctionnelle, Centre National de la Recherche Scientifique (CNRS), UMR 5203, Inserm U661, Universités \\ Montpellier I and II, 34094 Montpellier, France, ${ }^{5}$ Inserm, U842, Université de Lyon 1, UMR S842, 69003 Lyon, France, ${ }^{6}$ Centre d'Immunologie de Marseille \\ Luminy, CNRS, UMR 6102, Inserm, UMR 631, Université de la Méditerranée, 13288 Marseille, France, ${ }^{7}$ Brain Mind Institute, Ecole Polytechnique Fédérale \\ de Lausanne, CH-1015 Lausanne, Switzerland, and ${ }^{8}$ Center for Motor Neuron Biology and Disease, Columbia University, New York, New York 10032
}

Embryonic motoneurons from mutant SOD1 (mSOD1) mouse models of amyotrophic lateral sclerosis (ALS), but not wild-type motoneurons, can be triggered to die by exposure to nitric oxide (NO), leading to activation of a motoneuron-specific signaling pathway downstream of the death receptor Fas/CD95. To identify effectors of mSOD1-dependent cell death, we performed a proteomic analysis. Treatment of cultured mSOD1 motoneurons with NO led to a 2.5-fold increase in levels of collapsin response mediator protein 4a (CRMP4a). In vivo, the percentage of mSOD1 lumbar motoneurons expressing CRMP4 in mSOD1 mice increased progressively from presymptomatic to early-onset stages, reaching a maximum of $25 \%$. Forced adeno-associated virus (AAV)-mediated expression of CRMP4a in wild-type motoneurons in vitro triggered a process of axonal degeneration and cell death affecting $60 \%$ of motoneurons, whereas silencing of CRMP4a in mSOD1 motoneurons protected them from NO-induced death. In vivo, AAV-mediated overexpression of CRMP4a but not CRMP2 led to the death of $30 \%$ of the lumbar motoneurons and an $18 \%$ increase in denervation of neuromuscular junctions in the gastrocnemius muscle. Our data identify CRMP4a as a potential early effector in the neurodegenerative process in ALS.

\section{Introduction}

Amyotrophic lateral sclerosis (ALS) is a devastating neurodegenerative disease characterized by the selective and gradual loss of both upper and lower motoneurons. Most patients present a sporadic form of the disease, but much of our knowledge of the cellular and molecular pathogenic mechanisms comes from the study of familial forms. Approximately $10 \%$ of ALS cases are familial and of these up to $20 \%$ are caused by dominant mutations in superoxide dismutase 1 (SOD1). Correspondingly,

Received Nov. 2, 2009; accepted Nov. 30, 2009.

This work was supported by Inserm, an Agence Nationale de la Recherche fellowship to L.D., a Ministère de I'Education Nationale, de la Recherche et de la Technologie fellowship to N.B., a Society of Neurology fellowship to W.C., and grants from the Association Française contre les Myopathies, Association Française pour la Recherche sur la Sclérose Latérale Amyotrophique, and the European Union through the Network of Excellence "NeuroNE." We are especially thankful to V. Padrun and F. Pidoux (Ecole Polytechnique Fédérale de Lausanne, Lausanne, Switzerland) for AAV vector production. We thank all members of the Avenir team for their helpful comments throughout the work and in particular A. Moumen and J. Aebischer for their technical help. We thank Prof. J. Bockaert (Institut de Génomique Fonctionnelle, Montpellier, France) and Prof. J. Pouget (Centre Hospitalier Universitaire Timone, Marseille, France) for support and helpful discussions. Mass spectrometry experiments were performed using facilities of the Functional Proteomics Platform of Montpellier Languedoc-Roussillon (Montpellier, France).

Correspondence should be addressed to Dr. Brigitte Pettmann at the above address. E-mail: pettmann@inmed. univ-mrs.fr.

DOI:10.1523/JNEUROSC1.5411-09.2010

Copyright $\odot 2010$ the authors $\quad 0270-6474 / 10 / 300785-12 \$ 15.00 / 0$ transgenic mice overexpressing mutant forms of SOD1 (mSOD1) develop a motor syndrome closely resembling ALS (Bruijn et al., 2004). Multiple in vitro and in vivo studies have demonstrated that the actions of mSOD1 on motoneurons are both cell autonomous and nonautonomous (for review, see Boillee et al., 2006), but the sequence of events leading to motoneuron degeneration and subsequent death remains to be precisely mapped.

We previously showed that purified embryonic motoneurons from mSOD1 mice display increased susceptibility to activation of the Fas death receptor, which triggers a motoneuron-specific pathway (Raoul et al., 1999, 2002). We demonstrated that nitric oxide (NO), a downstream effector of Fas activation in motoneurons, increases the expression of Fas ligand and leads, in mSOD1 motoneurons but not in controls, to further production of NO through a feedback loop (Raoul et al., 2006b). This Fas/NO pathway is relevant in vivo since elements of the pathway are upregulated or misexpressed before the onset of symptoms in mSOD1 mice (Bendotti et al., 2004; Wengenack et al., 2004; Kiaei et al., 2007). Moreover, both pathway activation and disease onset are delayed by the intrathecal administration of siRNA to Fas (Locatelli et al., 2007). Therefore, a clearer understanding of the 
transcriptional and posttranslational changes triggered by Fas activation may potentially lead to identification of new therapeutic targets. In the present study, we used a proteomic approach to detect changes in motoneurons triggered by Fas in the mSOD1 context. One major protein whose expression we found to be upregulated was CRMP4 (collapsin response mediator protein 4).

CRMP4 is a member of a family of five developmentally regulated cytosolic phosphoproteins also known as TUCs or Ulips (for review, see Charrier et al., 2003). Functional studies in vitro and in vivo, focused mainly on CRMP2 and CRMP4, indicate that CRMPs may have positive or negative effects on neurite outgrowth depending on the cell type and the CRMP family member and isoforms (Quinn et al., 2003; Arimura et al., 2004; Quach et al., 2004; Alabed et al., 2007). The expression of CRMPs is significantly altered in models of adult neurodegenerative disease (Minturn et al., 1995; Yoshida et al., 1998; Pasterkamp and Verhaagen, 2001; Liu et al., 2003; Suzuki et al., 2003), but their precise links to the degenerative process have yet to be determined.

We show here that increased expression of CRMP4a, one of two splice variants of CRMP4, is observed in a subpopulation of lumbar motoneurons in mSOD1 mice starting at presymptomatic stages. Overexpression of CRMP4a in cultured motoneurons leads to inhibition of neurite outgrowth followed by cell death. On the contrary, inhibiting CRMP4 expression in NO-treated mSOD1 motoneurons through shRNA-CRMP4a prevents NOtriggered cell death. Adeno-associated virus (AAV)-mediated overexpression of CRMP4a in motoneurons in vivo leads to significant muscle denervation as well as reduction in motoneuron cell numbers. These data identify CRMP4a as a candidate early effector in motoneuron degeneration in the mSOD1 mouse model of ALS.

\section{Materials and Methods}

Animals. All animal experiments were performed in compliance with the European and national directives for the care and use of laboratory animals. CD1 mice were obtained from Iffa-Credo. Transgenic mice expressing mutant G85R (SOD1 ${ }^{\mathrm{G} 85 \mathrm{R}}$ ) and wild-type human SOD1 (SOD $1^{\mathrm{WT}}$ ) were kindly provided by Prof. D. Cleveland (University of California at San Diego, La Jolla, CA) and Prof. S. Przedborski (Columbia University, New York, NY); transgenic mice for mutant G93A $\left(\mathrm{SOD} 1^{\mathrm{G} 93 \mathrm{~A}}\right.$ ) were obtained from Transgenic Alliance. SOD1 ${ }^{\mathrm{G} 85 \mathrm{R}}$ (line 148) (Bruijn et al., 1997) and SOD1 WT mice (line 76) (Wong and Borchelt, 1995) were maintained as hemizygotes by crossing transgenic males with non-transgenic females of the same $\mathrm{C} 57 \mathrm{BL} / 6$ genetic background. SOD1 ${ }^{\text {G93A }}$ mice (line G1H) (Gurney et al., 1994) were maintained as hemizygotes by crossing transgenic males with non-transgenic females of the same B6/SJL genetic background. Offspring were genotyped as previously described (Raoul et al., 2002). During PCR genotyping of embryonic tail DNA (3-4h), embryos were kept at $4^{\circ} \mathrm{C}$ in Hibernate E medium (Invitrogen).

Reagents. DETANONOate, a NO donor, was purchased from Alexis Biochemicals. Primary antibodies rabbit polyclonal anti-CRMP4 (source 1), rabbit polyclonal anti-CRMP-2, rabbit polyclonal anti-vesicular acetylcholine transporter (VAChT), and mouse monoclonal anti-neuronal nuclei (NeuN) were purchased from Millipore. Rabbit polyclonal antiCRMP4 (source 2) was purchased from CovalAb. Mouse monoclonal anti-myc (9E10) was from Santa Cruz Biotechnology. Mouse monoclonal anti-GFP antibodies (a mixture of 7.1 and 13.1) were from Roche Diagnostics. Rabbit polyclonal anti-neurofilament ( $145 \mathrm{kDa})$ was from Millipore. $\alpha$-Bungarotoxin-tetramethylrhodamine conjugate was purchased from Invitrogen. Secondary antibodies Alexa Fluor 488 goat antimouse IgG, Alexa Fluor 488 goat anti-rabbit IgG, Cy3-conjugated AffiniPure goat anti-mouse IgG, and Cy3-conjugated AffiniPure goat anti-rabbit IgG were purchased from Invitrogen and Jackson ImmunoResearch Laboratories.
Expression constructs and recombinant adeno-associated virus vectors. Expression vectors for CRMP4a and CRMP2 were PCR amplified from pSG5-FLAG-CRMP4a and pSG5-FLAG-CRMP4a vectors (provided by V.R.), and the products were cloned into PGK1 (phosphoglycerol kinase 1)-6myc (pmyc) vectors using the following primers: CRMP4a, 5'-GGACATATGTCCCTACCAGGGCAAGAA-3' (forward) and 5'AATTGAGTCCCTACACTACAAT-3' (reverse); CRMP2, 5' -CCGAATTCCATGTCTTATCAGGGGAAGAAAAATATTC-3' (forward) and 5'-GGCTCGAGTTAGCCCAGGCTGGTGATGTTG-3' (reverse). Coding sequences for EGFP and myc-tagged CRMP2 or CRMP4a were cloned into AAV under the control of PGK1 promoter (Towne et al., 2008). shRNA stem sequences were as follows: sh1crmp4, 5'-AGTCCGATCTGAGTCCAAG-3'; sh2crmp4, 5' -AGTAGTAACTGCTAAGAGG-3'; sh1crmp4-mismatch, 5'-AGTCCTATATGAGTCCAAG-3'. These shRNAs were cloned into a bipartite PAAV vector in which expression of EGFP was placed under the control of the cytomegalovirus (CMV) promoter and the expression of the shRNAs under the control of the H1 promoter (pAAV-CMV-EGFP:H1-shRNA) (Towne et al., 2008). All clones were sequenced before use. Recombinant AAV serotype 6 vectors were produced using a helper-free system as previously described (Towne et al., 2008). Immunofluorescence titration with antibodies to GFP, CRMP2, and CRMP4a was achieved using NSC-34 cells and the viral titer expressed as transducing units (TU) per milliliter.

Cell cultures. Motoneuron cultures were prepared from embryonic day (E) 12.5 mouse spinal cords essentially as described previously by Arce et al. (1999), and modified by Raoul et al. (2002). Motoneurons were plated onto polyornithine/laminin-coated tissue culture plastic (Nunc) in supplemented Neurobasal medium in the presence of a mixture of neurotrophic factors (referred to as "NTFs"; $1 \mathrm{ng} / \mathrm{ml} \mathrm{BDNF,} 100 \mathrm{pg} / \mathrm{ml}$ GDNF, $10 \mathrm{ng} / \mathrm{ml} \mathrm{CNTF}$ ) added at the time of cell seeding. After $24 \mathrm{~h}$ in culture, motoneurons were treated by addition of $10 \mu \mathrm{m}$ DETANONOate (NO) diluted in Neurobasal medium. Unless otherwise stated, motoneurons were then incubated at $37^{\circ} \mathrm{C}$ for $24 \mathrm{~h}$ before fixation. Wherever indicated, motoneurons were electroporated before plating with DNA plasmids as described previously (Raoul et al., 2002) or infected after 24 h in vitro with the indicated AAV vectors.

Primary hippocampal neurons were cultured from E17.5 embryos of transgenic mSOD1 and control mice. Neurons were dissociated and plated at a cell density of 10,000 cells per well onto polyornithine/ laminin-coated four-well plates in Neurobasal medium supplemented with $1 \mathrm{~mm}$ glutamine and 2\% B27 (Invitrogen).

Expression analysis of myc-tagged CRMP2 or CRMP4a was performed by Western blot after transfection using Fugene 6 following the manufacturer's instructions (Roche Diagnostics) or by immunocytochemistry after infection of NSC34 motoneuron-like cells (Cashman et al., 1992) with the mentioned AAVs.

Expression inhibition analysis of EGFP-tagged CRMP4 or mismatched shRNAs was performed by Western blot of NSC34 cells after transfection with Lipofectamine 2000 following the manufacturer's instructions (Invitrogen) or by immunocytochemistry on motoneurons electroporated with the corresponding plasmids.

Preparation of protein samples from cultured motoneurons and twodimensional gel electrophoresis. After $24 \mathrm{~h}$ of treatment [i.e., 2 days in vitro (DIV)], cells were rinsed twice with PBS and lysed directly in the dish with $100 \mu$ l of lysis buffer. This extract was pooled in an Eppendorf tube with a $100 \mu \mathrm{l}$ wash and proteins were precipitated for $1 \mathrm{~h}$ at $4^{\circ} \mathrm{C}$ with trichloroacetic acid at a final concentration of $10 \%(\mathrm{w} / \mathrm{v})$. After centrifugation at 15,000 rpm for $15 \mathrm{~min}$, protein pellets were washed twice in diethyl ether and resuspended in $350 \mu \mathrm{l}$ of isoelectrofocusing medium containing $7 \mathrm{~m}$ urea, $2 \mathrm{~m}$ thiourea, 4\% 3-[(3-cholamidopropyl)dimethylammonio]-1-propanesulfonate, $8 \mathrm{mg} / \mathrm{ml}$ ampholines (preblended; isoelectric point range, 3.5-9.5; GE Healthcare), $100 \mathrm{~mm}$ DTT, $0.2 \%$ Tergitol NP7 (Sigma-Aldrich), and traces of bromophenol blue. Proteins $(30 \mu \mathrm{g} / \mathrm{gel})$ were first separated according to their isoelectric point values along nonlinear immobilized $\mathrm{pH}$-gradient strips ( $\mathrm{pH} 3-10 ; 18 \mathrm{~cm}$ long). Proteins were then resolved on $10-16 \%$ gradient gels and stained with silver, as described previously (Delcourt et al., 2005). Gels to be compared were always processed and stained in parallel. Gels were scanned using a computer-assisted densitometer. Spot detection, gel alignment, 
and spot quantification were performed with the ImageMaster 2D Platinium software (GE Healthcare).

MALDI-TOF mass spectrometry and protein identification. Protein spots were excised and digested in-gel using trypsin (Trypsin Gold; Promega), as described previously (Delcourt et al., 2005). Digested samples were dehydrated in a vacuum centrifuge, solubilized in $10 \mu \mathrm{l}$ of formic acid (2\%), desalted using C18 ZipTips [Millipore; elution with $10 \mu \mathrm{l}$ of $0.1 \%$ trifluoroacetic acid (TFA) in $50 \%$ acetonitrile], and concentrated to a $1 \mu \mathrm{l}$ volume. Aliquots of $0.3 \mu \mathrm{l}$, mixed with the same volume of $\alpha$-cyano-4-hydroxy-trans-cinnamic acid (10 $\mathrm{mg} / \mathrm{ml} 0.1 \%$ TFA in $50 \%$ acetonitrile), were deposited on a 384-well matrix-assisted laser desorption/ionization (MALDI) target using the dry droplet procedure and air dried at room temperature. Analyses were performed using an UltraFlex MALDI-time-of-flight (TOF)/TOF mass spectrometer (Bruker-Franzen Analytik) operating in the reflectron mode with a $20 \mathrm{kV}$ accelerating voltage and a $70 \mathrm{~ns}$ delayed extraction. Mass spectra were acquired in the automatic mode using the AutoXecute module of Flexcontrol ((BrukerFranzen Analytik ; laser power ranged from 30 to 70\%, 500 shots). Spectra were analyzed using FlexAnalysis software (Bruker-Franzen Analytik) and autoproteolysis peptides of trypsin (mass-to-charge ratios 842.51, 1045.56, and 2211.10) were used as internal calibrates. Peptides were selected in the mass range of $900-4000 \mathrm{Da}$. Identification of proteins was performed using the Mascot software package (version 2.1; Matrixscience) against the Swiss-Prot database. The following parameters were used for database interrogation: mass tolerance of $50 \mathrm{ppm}$ (although the mass accuracy of our analyses was usually better than $20 \mathrm{ppm}$ ); fixed chemical modification: carbamidomethylation of cysteine residues; variable chemical modification: oxidation of methionines; and matching peptides with one missed cleavage accepted only when they included two consecutive basic residues or when arginine or lysine residues were followed by one or several acidic residues inside the peptide amino acid sequence. Mascot scores of $>53$ were considered as significant $\left({ }^{*} p<\right.$ $0.05)$ for Swiss-Prot database interrogation.

$A A V$ injections of mice. BL6/SJL 40-d-old female mice were anesthetized with a mixture of Rompun and Imalgene and then injected in three different parts of the gastrocnemius muscles with $3 \times 10 \mu \mathrm{l}$ of PBS containing in total $5 \times 10^{6} \mathrm{AAV}$ infecting particles (infectious titer of AAV preparations was determined by counting EGFP- or mycexpressing NSC34 cells $24 \mathrm{~h}$ after their infection with serial dilutions of the AAV preparations). AAV-EGFP was injected into the left muscle (contralateral side), whereas AAV-6myc-CRMP2 or AAV-6mycCRMP4a were injected into the right muscle (ipsilateral side).

Immunocytochemistry. Embryonic motoneurons from wild-type, SOD $1^{\mathrm{G} 85 \mathrm{R}}$, SOD $1^{\mathrm{G} 93 \mathrm{~A}}$, or SOD $1^{\mathrm{WT}}$ mice were cultured on glass coverslips at a density of $5000 \mathrm{cells} / \mathrm{cm}^{2}$ and processed for immunocytochemistry as described previously (Raoul et al., 2002, 2005). Primary antibodies used were rabbit polyclonal anti-CRMP4 (1:500) and polyclonal anti-CRMP2 (1:500). Secondary antibodies used were Alexa Fluor 488- or 555-conjugated donkey anti-rabbit. Cells were visualized with a Leica DM IRB inverted fluorescence microscope and images were captured with a Kappa camera. Analysis of fluorescence intensity was performed on at least 50 motoneurons per condition using NIH Image 1.34s software (http://rsb.info.nih.gov/ij/).

Immunohistochemistry. Mice were perfused with PBS followed by $4 \%$ paraformaldehyde in PBS and the spinal cord (SC) as well as gastrocnemius muscles immediately dissected out. Tissues were incubated for $6 \mathrm{~h}$ in $4 \%$ paraformaldehyde at $4^{\circ} \mathrm{C}$. Lumbar parts of the SC and whole gastrocnemius muscles were incubated in $20 \%$ sucrose overnight at $4^{\circ} \mathrm{C}$. Tissues were embedded in optimal cutting temperature compound (CML). Sixteen-micrometer-thick transverse cryosections of the lumbar SC and 35- $\mu \mathrm{m}$-thick longitudinal sections of the gastrocnemius muscles (Frey et al., 2000) were collected onto Superfrost Plus slides (CML). Tissue sections were dried, permeabilized either in $0.1 \%$ Triton X-100PBS (SC) or in $1 \%$ Triton X-100-PBS (gastrocnemius muscles) for $1 \mathrm{~h}$ at room temperature, and then incubated in 4\% BSA (Sigma-Aldrich), 2\% goat serum (Invitrogen), and $0.1 \%$ Triton X-100 in PBS for $1 \mathrm{~h}$ to block nonspecific binding. Primary antibodies were added in the same blocking solution and incubated at $4^{\circ} \mathrm{C}$ overnight. For SC sections, rabbit polyclonal anti-CRMP4 (1:200) and rabbit polyclonal anti-CRMP2 (1:
$100)$ were used in combination with mouse monoclonal anti-NeuN (1: $800)$; for gastrocnemius muscle sections, rabbit polyclonal antineurofilament $145 \mathrm{kDa}(1: 1000)$ was used. Slides were incubated with appropriate secondary antibodies and, in the case of gastrocnemius muscle sections, together with $\alpha$-bungarotoxin-tetramethylrhodamine conjugate $(1: 500)$ for $1.5 \mathrm{~h}$ at room temperature and then stained with DAPI (1:10,000; Sigma-Aldrich) to visualize nuclei and mounted using Mowiol mounting medium. Cells were visualized with a Leica DM IRB inverted fluorescence microscope and images captured with a Kappa camera.

For AAV-injected mice, motoneuron immunohistochemistry in the spinal cord was performed on alternate slices with either mouse monoclonal anti-EGFP (1:200) or mouse monoclonal anti-myc (1:500) together with rabbit polyclonal anti-VAChT (1:500).

Western blot. Lumbar spinal cords were dissected from SOD ${ }^{\mathrm{G} 93 \mathrm{~A}}$ at various ages between 60 and $110 \mathrm{~d}$. SDS-PAGE and Western blotting were performed using protocols described previously (Raoul et al., 2002, 2005). Primary antibodies were anti-CRMP4 (pab0117, CovalAb; 1:2000) and anti-actin (AC-40, Sigma-Aldrich; 1:20,000). Proteins were detected using horseradish peroxidase (HRP)-conjugated secondary antibodies and visualized with the chemiluminescent HRP substrate (Millipore). Immunoblots images were quantified and normalized relative to actin levels using the NIH ImageJ software.

Statistical methods. For quantification of 2D gel spots, a nonparametric Kruskal-Wallis test was used. For all culture experiments in which the number of surviving or immunoreactive motoneurons was determined, three different experiments with three or four wells per condition were performed. If not otherwise indicated, results are expressed as percentages relative to control $\pm \mathrm{SD}$. Differences between treatments or genotypes were analyzed for their statistical significance by twotailed, unpaired Student's $t$ test. Results are expressed as percentages $\pm \mathrm{SD}\left({ }^{\star} p<0.05 ;{ }^{* *} p<0.01 ;{ }^{* *} p<0.001\right)$. To determine the statistical significance of the in vivo AAV infection experiments, the percentages of $\mathrm{EGFP}^{+} / \mathrm{VAChT}^{+}$and $\mathrm{myc}^{+} / \mathrm{VAChT}^{+}$in the spinal cord or the percentage of $\mathrm{NF}^{+} / \alpha$-bungarotoxin ${ }^{+}$versus $\mathrm{NF}^{-} / \alpha$ bungarotoxin ${ }^{+}$in the gastrocnemius muscle was subjected to a oneway ANOVA followed by a Bonferroni's post hoc test using the GraphPad Instat software.

\section{Results}

\section{Proteomic analysis of molecular changes in mutant SOD1 motoneurons exposed to nitric oxide}

To identify potential effectors of NO-induced death in MSOD1 motoneurons, we performed a differential proteomic analysis. Embryonic motoneurons isolated from E12.5 wild-type mice or mice overexpressing the G85R mutant form of SOD1 (SOD1 ${ }^{\mathrm{G} 85 \mathrm{R}}$ ) were cultured for $24 \mathrm{~h}$ in the presence of a mixture of neurotrophic factors (see Materials and Methods) before being treated, or not, for a further $24 \mathrm{~h}$ with the NO donor DETANONOate (referred to here as NO). Figure $1 A$ shows a typical silver-stained $2 \mathrm{D}$ gel of an extract of 100,000 motoneurons that yielded $\sim 30 \mu \mathrm{g}$ of total protein. Quantification of proteins, expressed as spot volumes, was performed from four different $2 \mathrm{D}$ gels per experimental condition, each obtained from different sets of cultured cells. The volume of each spot was first processed by background removal and then normalized relative to the volume of all spots. This comparative analysis revealed only six spots whose intensity reproducibly changed when motoneurons were treated with NO. A list of the analyzed proteins that showed changes is provided in supplemental Figure $1 A$ (available at www.jneurosci.org as supplemental material). The following different patterns were observed: the basal levels of two spots-14-3-3 $\zeta$ and peroxiredoxin-2-were higher in mSOD1 than in wild-type motoneurons, whereas the other four showed no difference. Levels of two spots-HSP90 and peroxiredoxin-2-were increased by NO treatment in both wild-type and mSOD1 motoneurons, whereas 
A

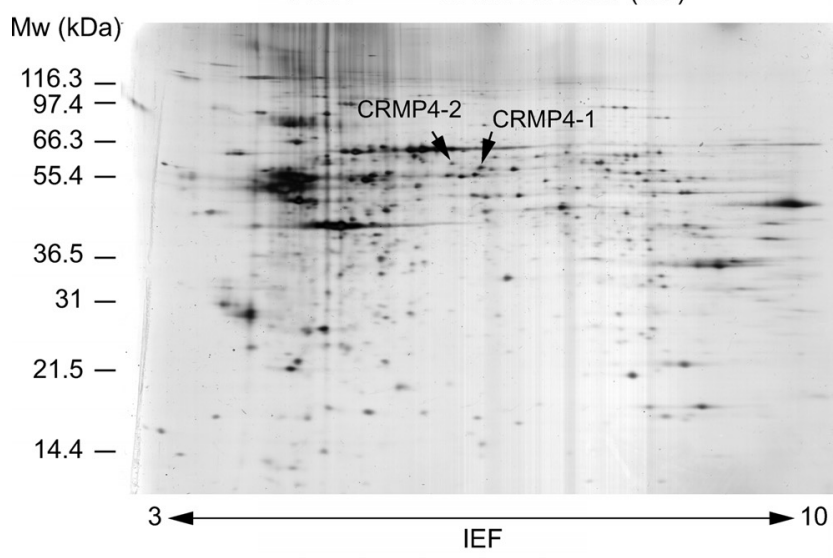

B
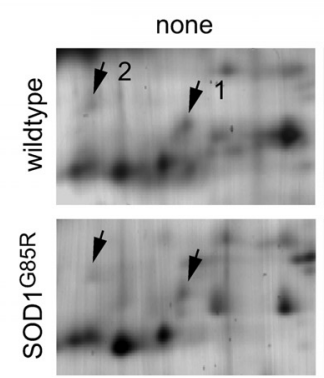

C

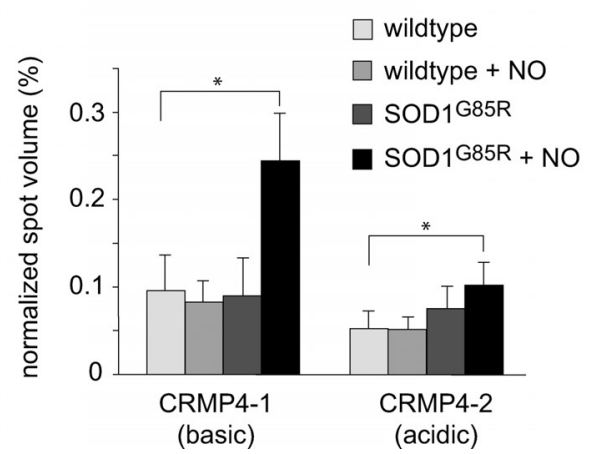

Figure 1. Proteomic analysis of $\mathrm{SOD} 1^{\mathrm{G} 85 \mathrm{R}}$ motoneurons exposed to nitric oxide reveals increased levels of CRMP4 expression. Whole-protein extracts from cultured motoneurons $(100,000$ neurons per $30 \mu \mathrm{g}$ of protein) were resolved on $2 \mathrm{D}$ gels (first dimension, $\mathrm{pH} 3-10$ nonlinear gradient; second dimension, $10-16 \%$ gradient). $A$, A representative silver-stained gel of N0-treated SOD $1{ }^{\mathrm{G} 85 \mathrm{R}}$ motoneurons is shown. Arrows indicate the position of spots corresponding to CRMP4. IEF, Isoelectrofocusing. Mw, Molecular weight. $\boldsymbol{B}$, Higher-magnification views of gel areas containing CRMP4 spots showing an increased expression of both CRMP4 forms (1, basic; 2, acidic) in the N0-stimulated SOD1 ${ }^{\text {G85R }}$ motoneurons. C, Quantification of the levels of the two forms of CRMP4. Results (spot volume relative to the volume of all detected spots) are means \pm SD of values obtained in four experiments performed on different sets of cultured neurons. ${ }^{*} p<0.05$ versus untreated wild-type motoneurons (nonparametric Kruskal-Wallis test).

calreticulin showed an increase in wild-type and a decrease in mSOD1 neurons. However, because our aim was to identify potential intermediates in the death pathway that is triggered by NO only in motoneurons from SOD $1{ }^{\mathrm{G} 85 \mathrm{R}}$ mice, but not in wild-type neurons, we focused on spots that only showed an NOdependent increase in mSOD1 motoneurons.

This pattern was observed only for two spots (Fig. $1 B, C$ ), both identified as CRMP4 by MALDI-TOF mass spectrometry (supplemental Fig. $1 B$, available at www.jneurosci.org as supplemental material). Since two splice-variant isoforms of CRMP4, named CRMP4a and CRMP4b, have been described (Quinn et al., 2003), we analyzed their expression in extracts of purified
E12.5 motoneurons. The CRMP4a isoform has an N-terminal region of 13 aa that is absent in the CRMP $4 \mathrm{~b}$ isoform. Conversely, the CRMP4b isoform has an N-terminal region of 126 aa that is absent in the CRMP4a isoform. RT-PCR using primers specific to the two different isoforms revealed significant expression of the CRMP4a isoform but failed to detect CRMP4b even after $35 \mathrm{cy}-$ cles of amplification (data not shown). In contrast, both forms were identified when amplifying testis and cortex cDNA (data not shown). This result is consistent with the apparent molecular weight of spots identified as CRMP4 on $2 \mathrm{D}$ gels $(\approx 60 \mathrm{kDa})$, which is similar to the theoretical molecular weight of CRMP4a $(62 \mathrm{kDa})$, and with the lack of detection of specific peptides of the CRMP4b sequence in MALDI-TOF analyses. Thus, following treatment of mSOD1 motoneurons with concentrations of $\mathrm{NO}$ that are sufficient to trigger mSOD1 motoneuron death but not that of wild-type motoneurons, only CRMP4, of all the proteins that can be detected at this level of sensitivity, appears to be upregulated in a manner that correlates with neuronal susceptibility.

\section{Exposure of cultured mSOD1 motoneurons to NO triggers increased expression of CRMP4a but not of CRMP2}

To validate and extend the conclusions from the proteomic analysis, we performed immunostaining to detect changes in CRMP4 levels in motoneurons from two different SOD1 mutants and compared the results to those for another CRMP family member. Motoneurons were isolated from wild-type, SOD1 ${ }^{\mathrm{G} 93 \mathrm{~A}}$, or SOD1 ${ }^{\text {G85R }}$ E12.5 embryonic spinal cords, cultured for $24 \mathrm{~h}$, treated or not with $10 \mu \mathrm{M} \mathrm{NO}$, and fixed $24 \mathrm{~h}$ later. Quantification of immunofluorescence intensity revealed significant increases in CRMP4 levels following NO treatment of motoneurons of both SOD1 ${ }^{\text {G93A }}\left(2.4 \pm 0.2\right.$-fold; $\left.{ }^{* * *} p<0.001\right)$ and SOD1 ${ }^{\text {G85R }}(2.7 \pm$ 0.2 -fold; ${ }^{* * *} p<0.001$ ) genotypes (Fig. $2 A, B$ ). Although the antibody used does not distinguish between isoforms, our reverse transcription-PCR analysis strongly suggests that this must reflect an increase in CRMP4a. We will therefore refer to CRMP4 as CRMP4a from here on. In contrast, no significant difference in CRMP4a immunoreactivity was detected in wild-type or SOD $1{ }^{\text {WT }}$ motoneurons treated with $\mathrm{NO}$ or in untreated mSOD1 motoneurons compared with controls (Fig. 2A,B). Because CRMP2 may have some functions in common with CRMP4, we analyzed its expression in parallel. No increase in CRMP2 expression was observed in any condition (Fig. $2 C, D$ ). Thus, treatment with $\mathrm{NO}$ at concentrations that lead to Fas-dependent death of mSOD1 but not wild-type motoneurons specifically triggers rapid accumulation of CRMP4a, but not of CRMP2, in an mSOD1-dependent manner.

Increased levels of CRMP4a in vivo in lumbar spinal cord motoneurons of presymptomatic mutant SOD1 mice Our results thus far demonstrated specific upregulation of CRMP4a in an in vitro paradigm thought to reflect the ALS disease process, but both the identification of CRMP4a and the validation of NO-triggered changes were based on embryonic motoneurons. To determine whether analogous changes might occur in adult motoneurons in the ALS disease context, we analyzed CRMP4a expression in vivo in SOD1 transgenic mice. Transverse sections of spinal cords from wild-type mice and from mice overexpressing the human wild-type SOD1 (SOD1 ${ }^{\mathrm{WT}}$ ) or the G93A or G85R mutant forms of the SOD1 protein were double immunostained for NeuN, a neuronal marker, and CRMP4a. Immunostaining of mSOD1 tissues was performed in parallel with age-matched wild-type controls of the corresponding ge- 

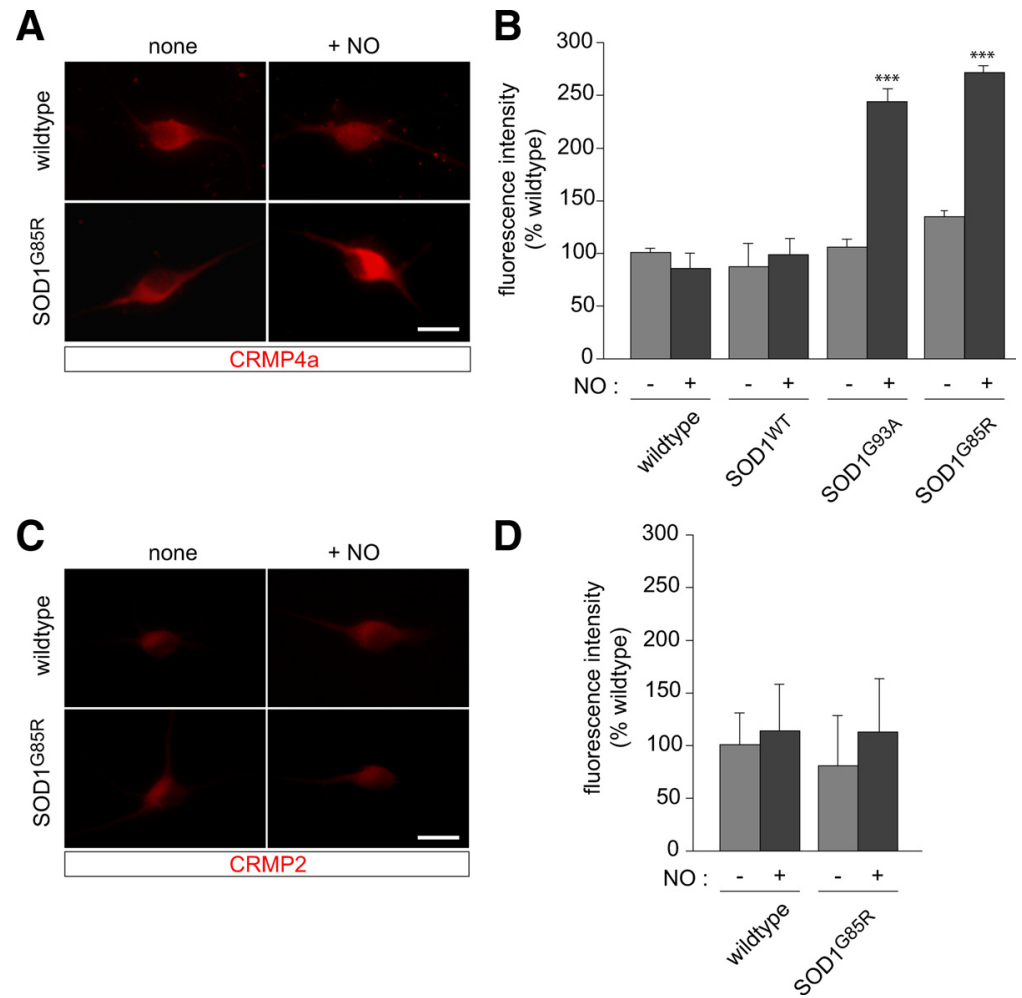

Figure 2. Exposure to $\mathrm{NO}$ in vitro induces an increase in CRMP4a, but not CRMP2, in mutant SOD1 motoneurons, but not controls. $A, C$, Immunostaining for CRMP4a ( $A$ ) or CRMP2 (C) in cultured wild-type or SOD1 ${ }^{\text {G85R }}$ motoneurons treated or not with NO for $24 \mathrm{~h}$. Scale bar, $25 \mu \mathrm{m}$. B, Quantification of CRMP4a immunofluorescence intensity in wild-type (WT), SOD1 WT, SOD1 ${ }^{\text {G93A }}$, or SOD1 ${ }^{\text {G85R }}$ motoneurons treated or not with NO. D, Quantification of CRMP2 immunofluorescence in WT and SOD1 ${ }^{\text {G85R }}$ motoneurons treated or not with NO. Analysis was performed using NIH ImageJ $1.34 \mathrm{~s}$ software on 50 motoneurons in each experimental condition in three independent experiments. ${ }^{* *} p<0.001$ versus untreated wild-type neurons.

netic background at different stages of disease, corresponding to the following postnatal ages: presymptomatic (150 d for SOD1 $1^{\text {G85R; }} 45$ and $60 \mathrm{~d}$ for SOD1 ${ }^{\mathrm{G} 93 \mathrm{~A}}$ ) and early-onset $(90 \mathrm{~d}$ for SOD $1^{\text {G93A }}$ ) stages (Fig. 3A). As a control for effects of human SOD1 overexpression unrelated to ALS, we also stained SOD 1 WT spinal cord sections at $200 \mathrm{~d}$. Following immunostaining, motoneurons were identified as large NeuN-positive neurons in the ventral horn of the spinal cord, and the fraction of these expressing levels of CRMP4a significantly above background was quantified (Fig. 3B). In SOD1 ${ }^{\text {G93A }}$ mutant spinal cord, the fraction of motoneurons strongly expressing CRMP4a was indistinguishable from controls at $45 \mathrm{~d}$, showed a 2.5 -fold increase in 60 -d-old presymptomatic animals, and reached a peak at the early-onset stage ( $90 \mathrm{~d})$. In these mice, the fraction of motoneurons expressing CRMP4a was $25 \pm 5 \%\left(n=3 ;{ }^{\star *} p<0.01\right)$, a value $>6$-fold higher than that for SOD $1{ }^{\mathrm{WT}}$ controls at $200 \mathrm{~d}$ (Fig. 3B). Values in SOD $1{ }^{\text {G85R }}$ mice also were increased 3- to 4 -fold above controls at presymptomatic stages, demonstrating that CRMP4a upregulation is a shared feature of disease triggered by two SOD1 mutants with quite different properties (Gurney et al., 1994; Bruijn et al., 1997). Western blot analysis of wild-type and SOD $1{ }^{\text {G93A }}$ lumbar spinal cord extracts probed with anti-CRMP4 confirmed a 2.5-fold increase in CRMP4a at 90 and $110 \mathrm{~d}$ (beginning of motoneuron loss), whereas no significant difference was seen at $60 \mathrm{~d}$ (Fig. 3C,D). Therefore, as predicted by the in vitro proteomic data, CRMP4a upregulation occurs at an early stage of the disease process in vivo, making CRMP4a a candidate effector that could potentially contribute to different aspects of the disease process, including axon withdrawal and motoneuron cell death.

\section{Overexpression of CRMP4a triggers a neurodegenerative process in cultured motoneurons, but not in hippocampal neurons}

The increased expression of CRMP4a observed in vivo could in principle reflect a role in the disease process but could also be part of a protective response by motoneurons to other degenerative processes. To distinguish between these possibilities, given the predictive value of the in vitro motoneuron system, we turned to it once again to investigate functional activities of CRMP4a in spinal motoneurons. We first focused on neurite outgrowth, because CRMPs have been reported to either enhance or inhibit axonal growth, depending on the CRMP isoform and the neuronal cell type (Inagaki et al., 2001; Quinn et al., 2003; Alabed et al., 2007; Rogemond et al., 2008).

We first generated a vector encoding myc-tagged CRMP4a under the control of the CAGGS (chicken $\beta$-actin promoter coupled to a CMV early enhancer) promoter and confirmed expression of the tagged protein following transfection of the motoneuron-like NSC34 cell line by Western blotting for myc (supplemental Fig. $2 A$, available at www.jneurosci.org as supplemental material). As a control, because there have been many reports of the effects of CRMP2 on axonal specification and/or growth, we used an analogous construct for myc-CRMP2 (supplemental Fig. $2 \mathrm{~A}$, available at www.jneurosci.org as supplemental material). To determine the effects of CRMP4a overexpression, suspensions of E12.5 motoneurons were coelectroporated with the myc-CRMP4a construct and another vector encoding EGFP. Immunostaining for myc $24 \mathrm{~h}$ after electroporation showed a coexpression of EGFP and myc in $92 \pm 5 \%$ of the motoneurons (data not shown). One day after seeding, we quantified neurite outgrowth of fluorescent motoneurons and compared values to those in cultures electroporated with empty myc vector together with the EGFP reporter. As we reported previously, all neurons at this stage have a single long process that corresponds to the axon because it expresses the microtubule-associated protein tau (data not shown). Overexpression of CRMP4a led to a $60 \%$ reduction in axonal length in motoneurons (supplemental Fig. 2B,C, available at www. jneurosci.org as supplemental material). In contrast, overexpression of CRMP2 in a similar manner had no significant effect on axonal outgrowth (supplemental Fig. $2 B, C$, available at www. jneurosci.org as supplemental material). To determine whether the effects of CRMP4a are cell type specific, we performed the same experiments using E17.5 hippocampal neurons, which have been used for most studies on CRMP2. In marked contrast to the results with motoneurons, neither CRMP4a nor CRMP2 affected neurite outgrowth from hippocampal neurons, even after $72 \mathrm{~h}$ in culture (supplemental Fig. $2 D, E$, available at www.jneurosci.org as supplemental material). Thus, although there are many differences between neurite outgrowth in vitro and axonal dieback in vivo, these data show that high levels of CRMP4a negatively affect 

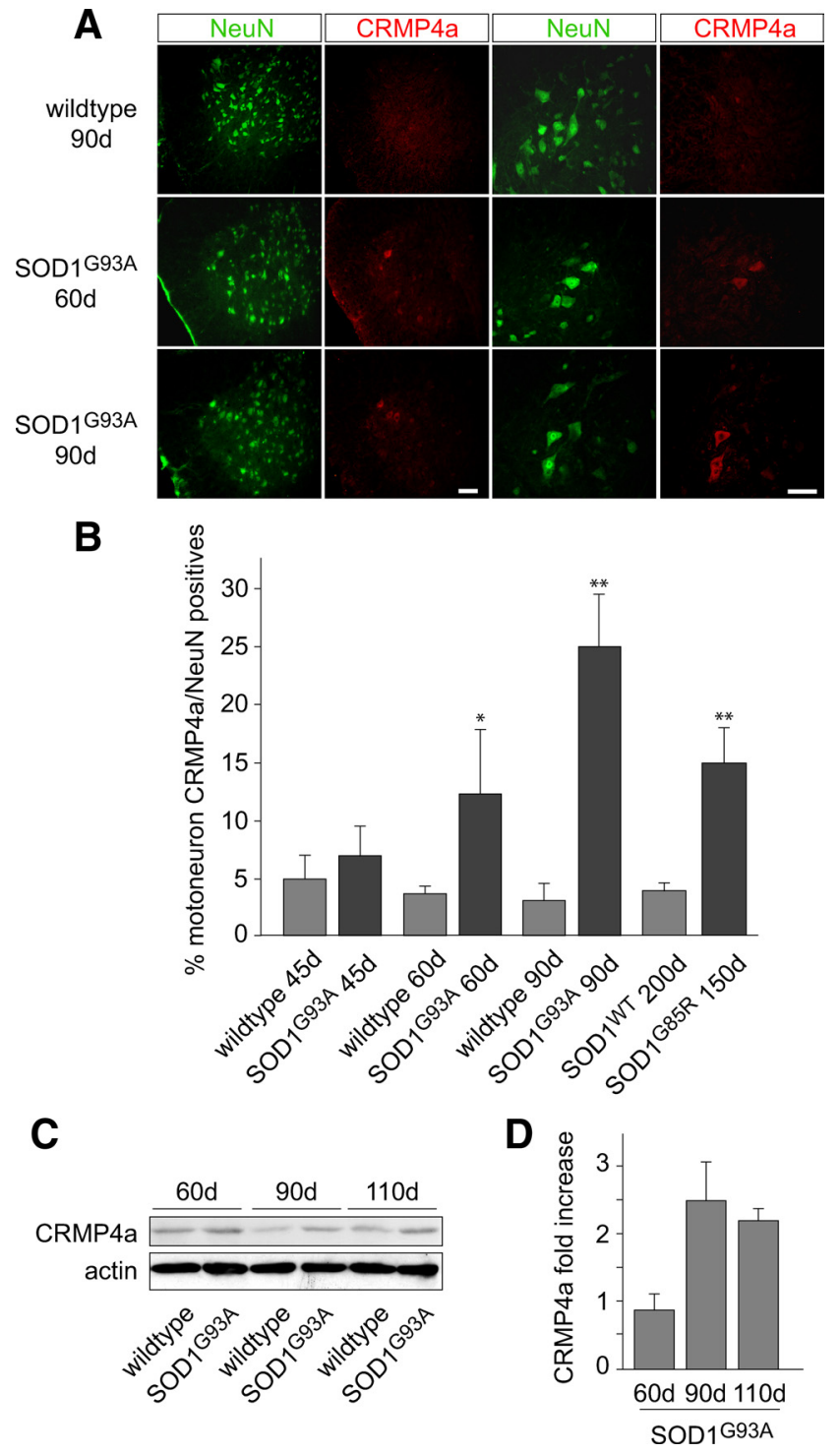

Figure 3. CRMP4a is upregulated in vivo in a subset of lumbar motoneurons of presymptomatic mutant SOD1 mice. $\boldsymbol{A}$, Wild-type ( $90 \mathrm{~d})$, presymptomatic ( $60 \mathrm{~d}$ ), and early symptomatic ( $90 \mathrm{~d}$ ) SOD $1{ }^{\mathrm{G} 3 \mathrm{~A}}$ mice were perfused and cryosections of their lumbar spinal cords were immunostained for NeuN (green) or CRMP4a (red). Scale bar, $100 \mu \mathrm{m}$. B, Quantification of CRMP4a-positive motoneurons as a percentage of NeuN-positive motoneurons in different mice strains (wild type, SOD1 ${ }^{\mathrm{WT}}$, SOD1 ${ }^{\mathrm{G} 85 \mathrm{R}}, \mathrm{SOD}_{1}{ }^{\mathrm{G} 93 \mathrm{~A}}$ ) at different stages of the disease: presymptomatic ( $150 \mathrm{~d}$ for SOD1 ${ }^{685 \mathrm{R}}$ and 45 or $60 \mathrm{~d}$ for SOD ${ }^{693 \mathrm{~A}}$ ) and early symptomatic $\left(90 \mathrm{~d}\right.$ for S0D1 $\left.{ }^{693 \mathrm{~A}}\right)\left(n=3 ;{ }^{*} p<0.05 ;{ }^{* *} p<0.01\right) . \mathbf{C}$, D, Western blot and quantification of CRMP4a in lumbar spinal cord extracts of wild-type and SOD $1{ }^{\text {G93A }}$ mice at 60,90 , and $110 \mathrm{~d} . n=2$, mean \pm SEM.

axonal dynamics in a manner that is dependent on neuronal class and is not shared by the close family member CRMP2.

It remained possible that the relatively stressful process of electroporation had rendered motoneurons more sensitive to the effects of CRMP4a. Moreover, we needed techniques for overexpression that could be used in vivo. We therefore developed vectors for viral delivery of CRMP cDNAs. We used AAVs, as they have been shown to be efficiently retrogradely transported to motoneurons when injected into muscles (Kaspar et al., 2003) and to demonstrate long-lasting expression, in particular when using the AAV-6 serotype (Towne et al., 2008). We produced AAV-myc-CRMP2 and AAV-myc-CRMP4a as well as AAVEGFP serotype 6 viruses and first confirmed their functionality in
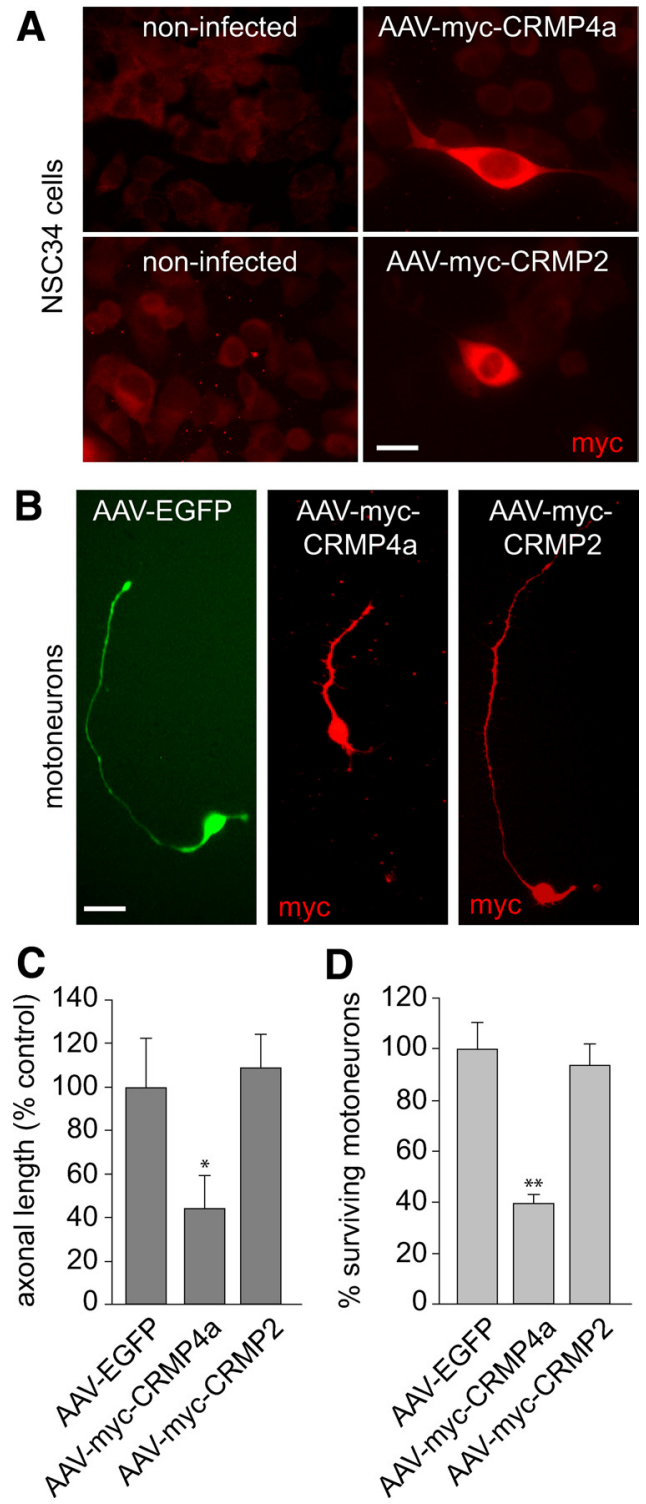

Figure 4. Overexpression of CRMP4a in motoneurons in vitro leads to decreased axonal outgrowth and cell death. A, NSC34 cells were infected with 10 TU per cell of AAV-myc-CRMP2 or AAV-myc-CRMP4a. Immunostaining $24 \mathrm{~h}$ later using an anti-myc antibody shows strong expression of both myc-CRMP2 and myc-CRMP4a. Scale bar, $10 \mu \mathrm{m}$. $\boldsymbol{B}-\boldsymbol{D}$, Motoneurons were infected with 10 TU/cell AAV-EGFP, AAV-myc-CRMP4a, or AAV-myc-CRMP2, and axonal length was measured directly (for AAV-EGFP) or after immunostaining for myc (AAV-myc-CRMP4a and AAV-myc-CRMP2) using the Neuron J software. Results in $\boldsymbol{B}$ and $\boldsymbol{C}$ show reduced axonal outgrowth with AAV-myc-CRMP4a, but not with AAV-myc-CRMP2, compared with AAV-EGFP. Scale bar $(\boldsymbol{B}), 30 \mu \mathrm{m}$. Survival of infected motoneurons measured $48 \mathrm{~h}$ after infection shows that overexpression of CRMP4a, but not of CRMP2, leads also to $60 \%$ cell death (D). $C$ and $\boldsymbol{D}$ show the average results of three different experiments. ${ }^{*} p<0.05 ;{ }^{* *} p<0.01$ versus control (AAV-EGFP).

vitro. Following infection of NSC34 cells (10 TU/cell), myctagged proteins were detected at high levels by immunostaining (Fig. 4A). In cultured neurons (Royo et al., 2008) and motoneurons (K. Langou and C. Raoul, unpublished results), infection efficiency with AAV serotype 6 was found to be $\sim 90 \%$. Motoneurons were therefore cultured for $24 \mathrm{~h}$ with neurotrophic factors before infection with AAV-EGFP, AAV-myc-CRMP4a, or AAVmyc-CRMP2, and $24 \mathrm{~h}$ later axonal lengths of infected motoneurons expressing EGFP or stained using anti-myc were measured. As with electroporation, viral overexpression of CRMP4a led to a 
A
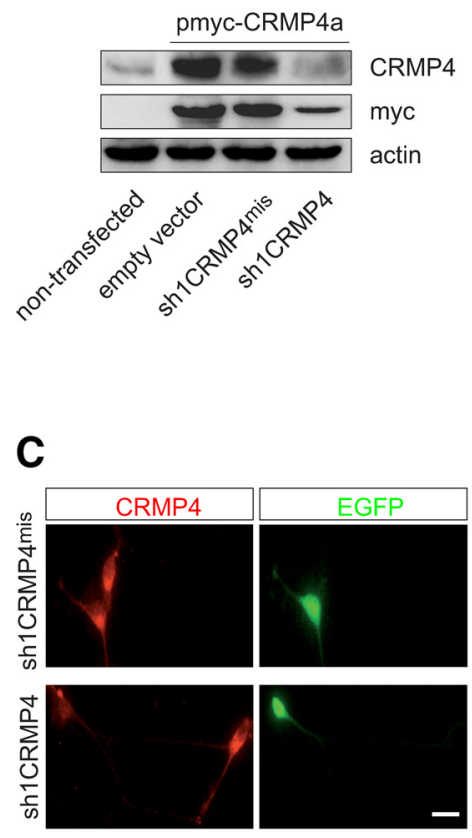

B

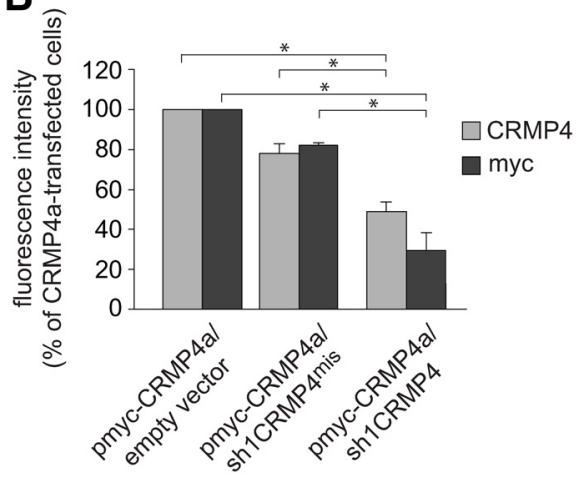

D

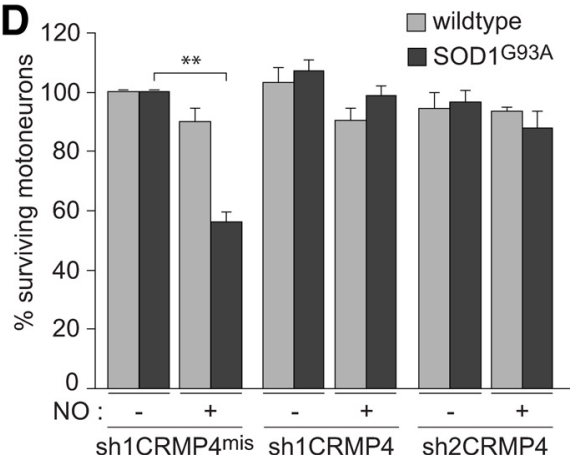

Figure 5. Silencing of CRMP4a expression protects mSOD1 motoneurons against death induced by nitric oxide. $A, B$, Silencing efficiency of sh1CRMP4 on CRMP4 and myc expression was shown by Western blots of NSC43 cells transfected with sh1CRMP4 or sh1CRMP4 ${ }^{\text {mis }}$ together with pPGK-myc-CRMP4a; $n=2 ;{ }^{* *} p<0.01$. C, The silencing efficiency of sh1CRMP4 was confirmed by immunocytochemistry on motoneurons transfected as in $A$ and $B ;$ Scale bar, $40 \mu \mathrm{m} ; n=2 ;{ }^{* *} p<0.01$. D, Motoneuron survival was assessed at $72 \mathrm{~h}$ in motoneurons electroporated at the time of seeding and treated or not with $\mathrm{N} 0$ at $24 \mathrm{~h}$. Electroporation with two different shRNAs to CRMP4 (sh1 and sh2), but not with the negative control sh1CRMP4 ${ }^{\text {mis }}$, prevented N0-induced death of mSOD1 motoneurons; $n=3 ;{ }^{* *} p<0.01$.

marked decrease in axonal length $\left(42 \pm 15 \%\right.$ of control; ${ }^{\star} p<$ 0.05 ) (Fig. $4 B, C$ ). In contrast, viral overexpression of CRMP2 had no effect on axon length, although the tagged protein was expressed at levels similar to those of CRMP4a (Fig. 4B,C).

The reduction in axon length we observed could reflect either a slowing of normal development in vitro or the beginning of a process of neuronal degeneration. To distinguish between these possibilities, we monitored survival of neurons infected with AAV-myc-CRMP4a over the first $2 \mathrm{~d}$ postinfection. After $24 \mathrm{~h}$, survival of motoneurons infected with AAV-myc-CRMP4a was already reduced to $60 \pm 12 \%$ of AAV-EGFP control values (data not shown). Neuronal loss continued over the next day and, at $48 \mathrm{~h}$ postinfection, survival of CRMP4a-infected motoneurons was only $40 \pm 3 \%$ of the AAV-EGFP control value. This cell death was a specific effect of CRMP4a, because motoneuron survival in cultures infected with AAV-myc-CRMP2 or AAV-EGFP was always $>80 \%$ and did not decrease with time (Fig. 4D). Thus, expression of CRMP4a, but not CRMP2, in cultured embryonic motoneurons is sufficient to trigger a neurodegenerative process involving reduction in axon length and cell death.

\section{Inhibiting CRMP4a expression in mSOD1 motoneurons in vitro prevents their $\mathrm{NO}$-induced death}

To test whether the increased expression of CRMP4a in mSOD1 motoneurons treated with $\mathrm{NO}$ played an essential role in their death, we designed several CRMP4-specific shRNAs and cloned them into a bipartite vector in which expression of EGFP was placed under the control of the CMV promoter and the expres- sion of the shRNAs under the control of the $\mathrm{H} 1$ promoter (Towne et al., 2008). Using Western blots, we first quantified their silencing effect in NSC34 cells transfected with either a CRMP4a expression vector (pmyc-CRMP4a) plus EGFP-shCRMP4 or the same expression vector plus the negative control EGFP-shCRMP4 ${ }^{\text {mis }}$ (sh1CRMP4 with two mismatched nucleotides). Two different (sh1 and sh2) shRNAs were shown to decrease CRMP4a expression levels by $50 \%$, whereas the mismatched shRNA had no significant effect (Fig. 5A,B and data not shown). Quantitative immunocytochemistry on electroporated motoneurons yielded similar results with a $64 \%$ inhibition of the fluorescence level with the CRMP4sh1RNA compared with the mismatched shRNA (Fig. $5 C$ and data not shown). We then tested the ability of CRMP4 silencing to prevent the death of NO-treated mSOD1 motoneurons. We electroporated motoneurons isolated from either wild-type or SOD1 ${ }^{\mathrm{G} 93 \mathrm{~A}}$ mice with the same combinations of vectors as described above, treated them or not $24 \mathrm{~h}$ later with $\mathrm{NO}$, and measured cell survival $48 \mathrm{~h}$ later. CRMP4a-specific shRNAs (sh1CRMP4 and sh2CRMP4), but not mismatched shRNA (sh1CRMP4 ${ }^{\mathrm{mis}}$ ), prevented NO-induced death of mSOD1 motoneurons without altering overall survival levels (Fig. 5D). Thus, this lossof-function approach indicated that the increased expression of CRMP4a triggered by NO in mSOD1 motoneurons is responsible for their death.

In vivo overexpression of CRMP4a, but not of CRMP2, in lumbar motoneurons induces motoneuron death and neuromuscular denervation in the gastrocnemius muscle The availability of AAV vectors allowed us to test whether increased levels of CRMP4a, as found in motoneurons of presymptomatic mSOD1 mice, could potentially be sufficient to trigger motoneuron degeneration and death. Intramuscular injection of $A A V$ viruses allows for highly efficient transduction of motoneurons in the corresponding pool. Gastrocnemius muscles of two groups of 40-d-old wild-type mice were injected with AAV-mycCRMP4a or AAV-myc-CRMP2, respectively, on one side, and with AAV-EGFP on the contralateral side. Three weeks after injection, sections of lumbar spinal cord were coimmunostained for vesicular acetylcholine transporter (VAChT), together with either EGFP (Fig. 6A) or myc (Fig. 6B,C). In each section, the percentage of VAChT-positive motoneurons that were EGFP positive or myc positive was counted (Fig. 6D). No significant difference in rate of infection (25-30\% of lumbar motoneurons) was found between the three virus preparations, allowing us to compare the effects of overexpressing different CRMPs at significant levels in vivo with those of viral overexpression of EGFP, which is known not to affect long-term survival (Towne et al., 2008).

To evaluate the functional effects of CRMP overexpression, we injected two groups of 1040 -d-old wild-type mice as in the 
previous experiment. Three months after injection (i.e., at $130 \mathrm{~d}$ ), animals were killed and alternate sections of the lumbar cord were immunostained for EGFP and VAChT and for myc and VAChT, respectively (Fig. 7A,B). Throughout the extent of the lumbar enlargement of the cord, numbers of surviving myc-positive and VAChT-positive motoneurons were measured in alternate sections, while EGFPpositive and VAChT-positive motoneurons were counted in the adjacent sections. Results were expressed as the percentage of myc (CRMP)-positive motoneurons relative to the percentage of EGFP-positive motoneurons. Using AAV expressing CRMP2, there was no significant decrease in motoneuron survival compared with that of EGFP (Fig. 7C). However, as in vitro, forced expression of CRMP4a, but not of CRMP2, led to significant motoneuron loss: survival of motoneurons expressing CRMP4a was only $71 \pm 2 \%\left({ }^{*} p<0.05\right)$ of the value for contralateral gastrocnemius motoneurons expressing EGFP. Thus, overexpression of CRMP4a is sufficient to induce motoneuron degeneration in vivo, supporting the hypothesis of an active role of CRMP4a in the onset and/or progression of the disease in $\mathrm{mSOD} 1$ mice. In vitro data indicated that CRMP4a overexpression induced both motoneuron death and a reduction in axonal length. We therefore asked whether overexpression of CRMP4a induced axonal changes in vivo. Neuromuscular junctions (NMJs) in AAV-treated mouse gastrocnemius muscles were examined for evidence of denervation at 3 months after injection. Longitudinal sections were stained for neurofilament and $\alpha$-bungarotoxin (AChR). Neurofilament-negative, $\alpha$-bungarotoxinpositive NMJs were classified as denervated (Fischer et al., 2004), whereas neurofilamentpositive, $\alpha$-bungarotoxin-positive NMJs were counted as innervated (Fig. 7D). Quantification shows that denervation of the gastrocnemius is significantly more pronounced ( $18 \%$ of NMJs showing denervation) in mice injected with AAV-myc-CRMP4a than in mice injected with AAV-myc-CRMP2 or AAV-myc-EGFP $(<5 \%$ denervation) (Fig. 7E). Thus, overexpression of CRMP4a in vivo triggers both motoneuron death and muscle denervation, two characteristic phenotypes of ALS in mSOD1 mice.

\section{Discussion}

We have identified CRMP4a as a novel potential effector of neurodegeneration in the mutant SOD1 model of ALS. Several arguments support such a role. First, CRMP4a is one of a very small group of proteins that show significant upregulation in an in vitro model of mSOD1-dependent motoneuron death. Second, CRMP4a levels progressively increase in vivo in a subset of motoneurons in mSOD1 mice at presymptomatic and early symptomatic stages. Third, overexpression of CRMP4a in mopreparations.
A
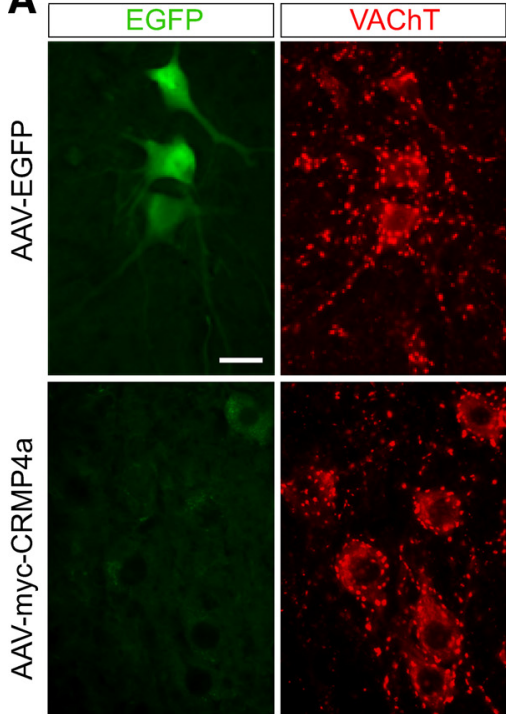

C
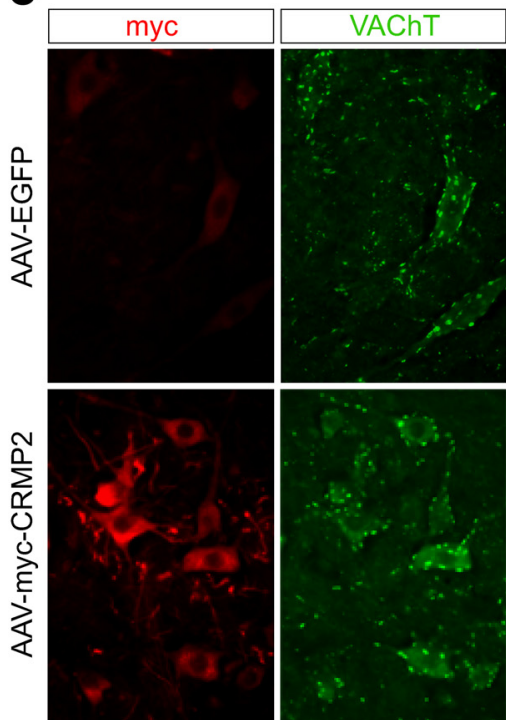

B

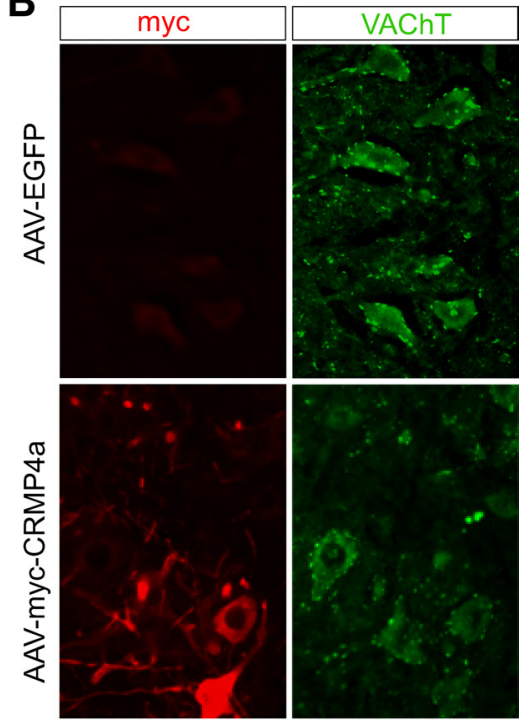

D

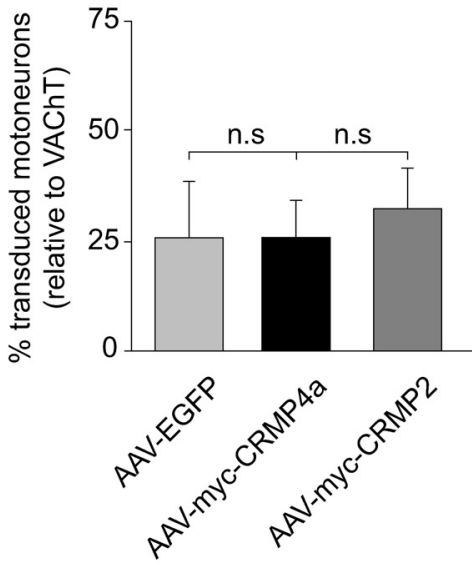

Figure 6. Characterization of viral infection efficiency in vivo. A-C, Experiment assessing the functionality and titration of the AAV vector preparations. Three weeks after injection with AAV-EGFP (contralateral side) and AAV-myc-CRMP2 or AAV-mycCRMP4a (ipsilateral side) in the gastrocnemius muscle, double immunostaining for EGFP and VAChT $(\boldsymbol{A})$ or myc and VAChT $(\boldsymbol{B}, \boldsymbol{C})$ was performed on lumbar spinal cord sections and shows good expression of all overexpressed proteins on the injected side and no significant staining on the contralateral side. Scale bar (in $\boldsymbol{A}) \boldsymbol{A}-\boldsymbol{C}, 25 \mu \mathrm{m}$. $\boldsymbol{D}$, Counting of EGFP-, myc-, and VAChT-positive motoneurons on serial sections through the lumbar spinal cord shows no statistically significant difference between the three

toneurons in vitro and in vivo is sufficient to trigger their degeneration and death, whereas inhibiting CRMP4a expression in mSOD1 motoneurons prevents NO-induced death. These effects are specific to CRMP4a and motoneurons as follows: the related protein CRMP2 is not upregulated in MSOD1 mice and is not sufficient to trigger motoneuron death, whereas hippocampal neurons are not affected by CRMP4a overexpression. These results further validate our model of Fas/NO-triggered motoneuron cell death as a reliable predictor of early ALS-related changes in vivo.

Definitive evidence for a role of CRMP4a in ALS pathogenesis will require loss-of-function approaches in $\mathrm{MSOD} 1$ mice in vivo. One approach to reducing CRMP4a levels would be to use AAVshRNA vectors (Raoul et al., 2005, 2006a). AAV2 vectors encoding shRNA to human SOD1 were injected into hindlimb muscles 

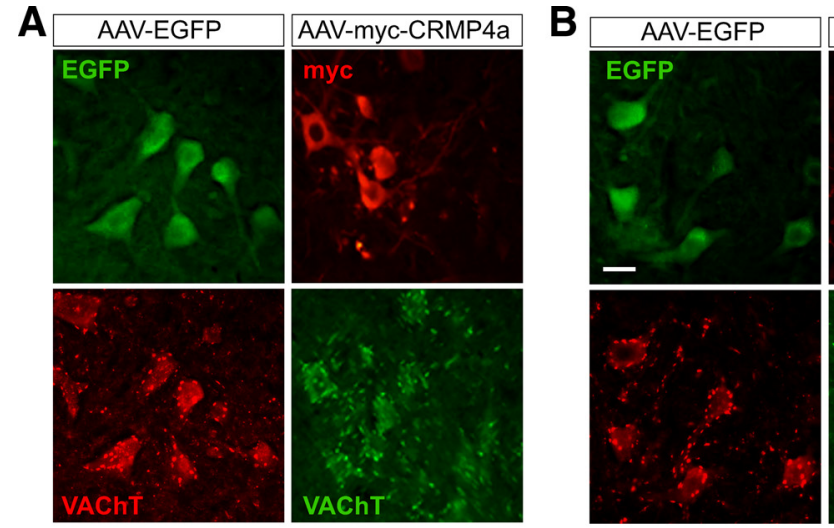

\section{C}

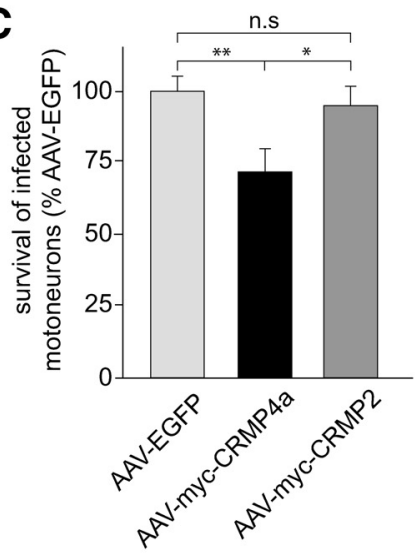

D

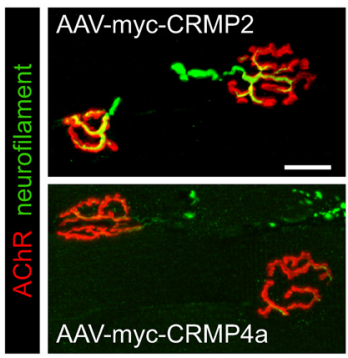

E

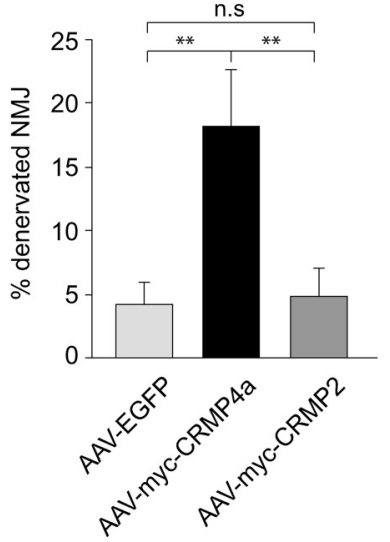

Figure 7. Viral overexpression of CRMP4a in vivo leads to motoneuron degeneration and muscle denervation. $A, B$, Two cohorts of 10 mice were injected in the gastrocnemius muscle with AAV-EGFP on the contralateral side and either AAV-myc-CRMP2 $(\boldsymbol{A})$ or AAV-myc-CRMP4a $(\boldsymbol{B})$ on the ipsilateral side. Ninety days later, mice were perfused with fixative, and spinal cords and muscle were dissected. $\boldsymbol{A}$-C, Double immunostaining was performed on alternate sections of the lumbar spinal cord, one for EGFP and VAChT, the adjacent one for myc and VAchT. Scale bar (in $\boldsymbol{B}) \boldsymbol{A}, \boldsymbol{B}, 25 \mu \mathrm{m}$. $\boldsymbol{C}$, Positive immunostained motoneurons were counted throughout the lumbar spinal cord. A $30 \%$ decrease in motoneuron survival is observed only in mice overexpressing CRMP4a, compared with EGFP. D, E, Gastrocnemius muscle sections were immunostained for neurofilament (NF) and incubated with $\alpha$-bungarotoxin. NMJs were counted as innervated when NF and $\alpha$-bungarotoxin (AChR) colocalized ( $\boldsymbol{D}$, top) and as denervated when NF staining was absent (D, bottom). $\boldsymbol{E}$, An $18 \%$ increase in denervated NMJs was specifically observed in mice overexpressing CRMP4a. ${ }^{*} p<0.05 ;{ }^{* *} p<0.01$, ANOVA one-factor analysis.

of mSOD1 mice and led to a significant delay in the loss of grip strength (Miller et al., 2005). Nevertheless, because expression was restricted to a limited number of motoneurons, there was no long-term effect on survival or motor behavior. A more complete evaluation of the role of CRMP4 would involve crossing mice with targeted deletions of CRMP4 with mSOD1 mice to determine whether this confers benefit for survival, muscle innervation, and/or motoneuron numbers. Unfortunately, although
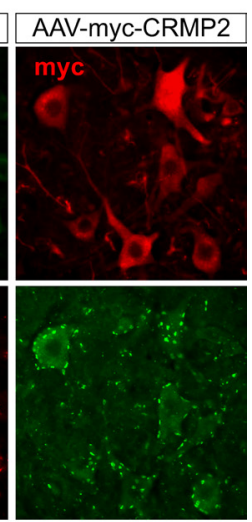

null-mutant mice have been developed for CRMP1 (Charrier et al., 2006; Su et al., 2007) and CRMP3 (Quach et al., 2008a,b), no knock-out strains exist for CRMP4.

The results of our initial proteomic approach are clearly validated by expression studies on mSOD1 motoneurons in vitro and in vivo. Yet, despite the existence of a considerable number of prior microarray and proteomic studies focusing on mutant SOD1 mice, this is the first report to implicate CRMP4a. There are several potential explanations for this. One reason may be the highly selective filter we put on the proteomic data: we searched for proteins that would be specifically regulated by NO only in the mutant SOD1 context. Our published data led us to believe that these would constitute a subset of proteins activated by Fas and involved in SOD1related cell death (Raoul et al., 2002). In contrast, a comparable proteomic study analyzed the effects of stable overexpression of mSOD1 in the motoneuron-like cell line NSC34 (Allen et al., 2003). This study identified several changes that could be confirmed in postmortem material from ALS patients. However, these cells are clearly not identical to primary motoneurons, and it is possible that high levels of CRMP4a were inconsistent with generation of stable mSOD1 overexpressors. Several groups have used a proteomic approach to analyze spinal cord extracts of mutant SOD1 mice at different stages of the disease (Perluigi et al., 2005; Massignan et al., 2007), but the fact that the affected motoneurons represent only a small minority of spinal cord cells may conceal motoneuron-specific changes such as the one we report. Using a microarray approach, Saxena et al. (2009) recently reported a comparative analysis of longitudinal molecular changes in vulnerable (fast) and resistant (slow) motoneurons innervating different muscle compartments in mSOD1 mice. There are dynamic changes in expression levels of multiple genes early in the disease process, culminating in the activation of an unfolded protein response specifically in vulnerable neurons. Correspondingly, disease progression was slowed by salubrinal, which protects against ER stress. Thus, analysis of early molecular changes in diseased neurons is a valid strategy for identifying candidate therapeutics. However, although microarray approaches are extremely useful, they necessarily detect modifications in accumulation or stability only of mRNA, not of protein.

Two previous reports have linked CRMP family members to neurodegenerative disorders. Increased expression of CRMPs has been observed in Alzheimer's disease, in which CRMP2 was 
found to be associated with tangles (Yoshida et al., 1998). In bovine spongiform encephalopathy (BSE), CRMP4 was specifically upregulated in the brain of BSE-infected mice (Auvergnon et al., 2009). In both cases, it was unclear whether upregulation reflected an attempt by the neurons to block degeneration, a protective effect, or to accelerate the disease process. Our data on the ability of CRMP4a to trigger axonal degeneration and motoneuron death argue for an active role in this and other degenerative processes. It will therefore be interesting to determine whether CRMP4a is also upregulated during the development of the SOD1-linked and sporadic forms of ALS in human patients. In the microarray data of Jiang et al. (2005) on laser-captured human postmortem motoneurons, CRMP4 mRNA levels show no change in ALS, whereas CRMP2 is downregulated 2.7-fold. This may reflect a difference between sporadic and SOD1-linked ALS, but it is also possible that the most resistant motoneurons, which persist in late-stage patients, do not overexpress CRMP4 to a detectable extent.

Indeed, it was striking that in our study the fraction of motoneurons expressing high levels of CRMP4a in mSOD1 lumbar spinal cord never exceeded 25\%, whereas the percentage of motoneuron loss in the SOD $1^{\mathrm{G} 93 \mathrm{~A}}$ strain of mice we used has been estimated at $\sim 40 \%$ at symptomatic stages (Bendotti et al., 2004). There are three potential explanations for this fractional labeling. First, at any given point in time only a fraction of those motoneurons destined to die may express high levels of CRMP4, perhaps reflecting the progressive loss of those motoneurons expressing the highest levels of CRMP4a. Second, a subset of motoneurons may die using other pathways/effectors. If the second hypothesis were true, it would be intriguing to determine whether high CRMP4 expressors correspond to particularly susceptible groups, such as the fast fatigable motoneurons innervating the lateral gastrocnemius muscle (Frey et al., 2000), and whether CRMP4 fails to be expressed in the motor nuclei (oculomotor and Onuf's nucleus) known to be ALS resistant (Mannen et al., 1982; Bergmann, 1993).

In evaluating the role of CRMP4 in ALS pathology, one important question concerns the relative timing of the changes described here and others reported in the literature. After a neonatal period in which motoneuron excitability is altered (Durand et al., 2006; van Zundert et al., 2008), the first morphological changes to be detected are at the neuromuscular junction where motor axons die back, leading to skeletal muscle paralysis that is only transiently overcome by regenerative axon sprouting (Frey et al., 2000; Fischer et al., 2004; Schaefer et al., 2005). Fast motor units are more vulnerable than slow motor units to axonal dieback, even within the same muscle (Pun et al., 2006). Following this phase, motoneuron cell bodies begin to die in the spinal cord through a process with some features of programmed cell death (Martin, 1999; Przedborski, 2004; Wengenack et al., 2004). In the $\mathrm{G} 1 \mathrm{H}$ line of $\mathrm{mSOD} 1^{\mathrm{G} 93 \mathrm{~A}}$ mice (the one we used), onset of the disease is around $90 \mathrm{~d}$, with motoneuron loss starting at around $110 \mathrm{~d}$ (for review, see Turner and Talbot, 2008). Our results showing significant upregulation of CRMP4a in mSOD1 motoneurons from $60 \mathrm{~d}$ onward would position the action of CRMP4a at onset and early disease. This would place it among the earliest identified potential effectors in the mSOD $1{ }^{\mathrm{G} 93 \mathrm{~A}}$ mice, allowing it to potentially play a role in muscle denervation in the most susceptible motor units.

How might elevated levels of CRMP4a contribute to the ALS disease process? It is not possible from our data to determine whether the effects on axonal length and on cell survival are part of a single mechanism, but their close temporal coincidence in vitro would argue for this. The fact that overexpressing CRMP4a leads to both axonal dieback and motoneuron death argues for a critical role of CRMP4a in ALS pathogenesis, as these two features are hallmarks of the disease (Bruijn et al., 2004; Fischer et al., 2004). Although little is known about cell death triggered by CRMPs, a number of studies have implicated them in regulation of neurite outgrowth. Proposed mechanisms for the actions of CRMP2, the most studied, involve regulation of microtubule assembly (Fukata et al., 2002), endocytosis of adhesion molecules (Nishimura et al., 2003), reorganization of actin filaments (Kawano et al., 2005), and axonal trafficking of proteins (Kimura et al., 2005). However, no such mechanistic studies have been reported for CRMP4. Because in our hands CRMP2 showed no activity in motoneurons, and CRMP4a no activity in hippocampal neurons, the mechanisms of degeneration and death triggered by CRMP4a are likely to be different from those activated by other CRMPs. If, like the Fas/NO pathway by which CRMP4a expression is triggered, they are motoneuron specific, they are of potentially high significance as therapeutic targets.

Overall, molecular profiling of an in vitro model of ALS has led us to discover a potential effector whose pattern of expression in mSOD1 ALS mice and whose properties when overexpressed, fit it well for a role in the disease process. Further confirmation of the significance of CRMP4a will require loss-of-function studies in vivo and expression studies in human postmortem spinal cord, but the pathways triggered by Fas, NO, and CRMP4a itself are already worthy of further investigation as potential levels at which to intervene therapeutically.

\section{References}

Alabed YZ, Pool M, Ong Tone S, Fournier AE (2007) Identification of CRMP4 as a convergent regulator of axon outgrowth inhibition. J Neurosci 27:1702-1711.

Allen S, Heath PR, Kirby J, Wharton SB, Cookson MR, Menzies FM, Banks RE, Shaw PJ (2003) Analysis of the cytosolic proteome in a cell culture model of familial amyotrophic lateral sclerosis reveals alterations to the proteasome, antioxidant defenses, and nitric oxide synthetic pathways. J Biol Chem 278:6371-6383.

Arce V, Garces A, de Bovis B, Filippi P, Henderson C, Pettmann B, deLapeyriere O (1999) Cardiotrophin-1 requires LIFRbeta to promote survival of mouse motoneurons purified by a novel technique. J Neurosci Res 55:119-126.

Arimura N, Menager C, Fukata Y, Kaibuchi K (2004) Role of CRMP-2 in neuronal polarity. J Neurobiol 58:34-47.

Auvergnon N, Reibel S, Touret M, Honnorat J, Baron T, Giraudon P, Bencsik A (2009) Altered expression of CRMPs in the brain of bovine spongiform encephalopathy-infected mice during disease progression. Brain Res 1261:1-6.

Bendotti C, Atzori C, Piva R, Tortarolo M, Strong MJ, DeBiasi S, Migheli A (2004) Activated p38MAPK is a novel component of the intracellular inclusions found in human amyotrophic lateral sclerosis and mutant SOD1 transgenic mice. J Neuropathol Exp Neurol 63:113-119.

Bergmann M (1993) Motor neuron disease/amyotrophic lateral sclerosislessons from ubiquitin. Pathol Res Pract 189:902-912.

Boillee S, Vande Velde C, Cleveland DW (2006) ALS: a disease of motor neurons and their nonneuronal neighbors. Neuron 52:39-59.

Bruijn LI, Becher MW, Lee MK, Anderson KL, Jenkins NA, Copeland NG, Sisodia SS, Rothstein JD, Borchelt DR, Price DL, Cleveland DW (1997) ALS-linked SOD1 mutant G85R mediates damage to astrocytes and promotes rapidly progressive disease with SOD1-containing inclusions. Neuron 18:327-338.

Bruijn LI, Miller TM, Cleveland DW (2004) Unraveling the mechanisms involved in motor neuron degeneration in ALS. Annu Rev Neurosci 27:723-749.

Cashman NR, Durham HD, Blusztajn JK, Oda K, Tabira T, Shaw IT, Dahrouge S, Antel JP (1992) Neuroblastoma $\times$ spinal cord (NSC) hybrid cell lines resemble developing motor neurons. Dev Dyn 194:209-221.

Charrier E, Reibel S, Rogemond V, Aguera M, Thomasset N, Honnorat J 
(2003) Collapsin response mediator proteins (CRMPs): involvement in nervous system development and adult neurodegenerative disorders. Mol Neurobiol 28:51-64.

Charrier E, Mosinger B, Meissirel C, Aguera M, Rogemond V, Reibel S, Salin P, Chounlamountri N, Perrot V, Belin MF, Goshima Y, Honnorat J, Thomasset N, Kolattukudy P (2006) Transient alterations in granule cell proliferation, apoptosis and migration in postnatal developing cerebellum of CRMP1 -/ - mice. Genes Cells 11:1337-1352.

Delcourt N, Jouin P, Poncet J, Demey E, Mauger E, Bockaert J, Marin P, Galeotti N (2005) Difference in mass analysis using labeled lysines (DIMAL-K): a new, efficient proteomic quantification method applied to the analysis of astrocytic secretomes. Mol Cell Proteomics 4:1085-1094.

Durand J, Amendola J, Bories C, Lamotte d'Incamps B (2006) Early abnormalities in transgenic mouse models of amyotrophic lateral sclerosis. J Physiol Paris 99:211-220.

Fischer LR, Culver DG, Tennant P, Davis AA, Wang M, Castellano-Sanchez A, Khan J, Polak MA, Glass JD (2004) Amyotrophic lateral sclerosis is a distal axonopathy: evidence in mice and man. Exp Neurol 185:232-240.

Frey D, Schneider C, Xu L, Borg J, Spooren W, Caroni P (2000) Early and selective loss of neuromuscular synapse subtypes with low sprouting competence in motoneuron diseases. J Neurosci 20:2534-2542.

Fukata Y, Itoh TJ, Kimura T, Menager C, Nishimura T, Shiromizu T, Watanabe H, Inagaki N, Iwamatsu A, Hotani H, Kaibuchi K (2002) CRMP-2 binds to tubulin heterodimers to promote microtubule assembly. Nat Cell Biol 4:583-591.

Gurney ME, Pu H, Chiu AY, Dal Canto MC, Polchow CY, Alexander DD, Caliendo J, Hentati A, Kwon YW, Deng HX, Chen W, Zhai P, Sufit RL, Siddique T. (1994) Motor neuron degeneration in mice that express a human $\mathrm{Cu}, \mathrm{Zn}$ superoxide dismutase mutation. Science 264:1772-1775.

Inagaki N, Chihara K, Arimura N, Menager C, Kawano Y, Matsuo N, Nishimura T, Amano M, Kaibuchi K (2001) CRMP-2 induces axons in cultured hippocampal neurons. Nat Neurosci 4:781-782.

Jiang YM, Yamamoto M, Kobayashi Y, Yoshihara T, Liang Y, Terao S, Takeuchi H, Ishigaki S, Katsuno M, Adachi H, Niwa J, Tanaka F, Doyu M, Yoshida M, Hashizume Y, Sobue G (2005) Gene expression profile of spinal motor neurons in sporadic amyotrophic lateral sclerosis. Ann Neurol 57:236-251.

Kaspar BK, Lladó J, Sherkat N, Rothstein JD, Gage FH \{2003) Retrograde viral delivery of IGF-1 prolongs survival in mouse ALS model. Science 301:839-842.

Kawano Y, Yoshimura T, Tsuboi D, Kawabata S, Kaneko-Kawano T, Shirataki H, Takenawa T, Kaibuchi K (2005) CRMP-2 is involved in kinesin-1-dependent transport of the Sra-1/WAVE1 complex and axon formation. Mol Cell Biol 25:9920-9935.

Kiaei M, Kipiani K, Calingasan NY, Wille E, Chen J, Heissig B, Rafii S, Lorenzl S, Beal MF (2007) Matrix metalloproteinase-9 regulates TNF-alpha and FasL expression in neuronal, glial cells and its absence extends life in a transgenic mouse model of amyotrophic lateral sclerosis. Exp Neurol 205:74-81.

Kimura T, Watanabe H, Iwamatsu A, Kaibuchi K (2005) Tubulin and CRMP-2 complex is transported via Kinesin-1. J Neurochem 93:1371-1382.

Liu PC, Yang ZJ, Qiu MH, Zhang LM, Sun FY (2003) Induction of CRMP-4 in striatum of adult rat after transient brain ischemia. Acta Pharmacol Sin 24:1205-1211.

Locatelli F, Corti S, Papadimitriou D, Fortunato F, Del Bo R, Donadoni C, Nizzardo M, Nardini M, Salani S, Ghezzi S, Strazzer S, Bresolin N, Comi GP (2007) Fas small interfering RNA reduces motoneuron death in amyotrophic lateral sclerosis mice. Ann Neurol 62:81-92.

Mannen T, Iwata M, Toyokura Y, Nagashima K (1982) The Onuf's nucleus and the external anal sphincter muscles in amyotrophic lateral sclerosis and Shy-Drager syndrome. Acta Neuropathol 58:255-260.

Martin LJ (1999) Neuronal death in amyotrophic lateral sclerosis is apoptosis: possible contribution of a programmed cell death mechanism. J Neuropathol Exp Neurol 58:459-471.

Massignan T, Casoni F, Basso M, Stefanazzi P, Biasini E, Tortarolo M, Salmona M, Gianazza E, Bendotti C, Bonetto V (2007) Proteomic analysis of spinal cord of presymptomatic amyotrophic lateral sclerosis G93A SOD1 mouse. Biochem Biophys Res Commun 353:719-725.

Miller TM, Kaspar BK, Kops GJ, Yamanaka K, Christian LJ, Gage FH, Cleveland DW (2005) Virus-delivered small RNA silencing sustains strength in amyotrophic lateral sclerosis. Ann Neurol 57:773-776.
Minturn JE, Fryer HJ, Geschwind DH, Hockfield S (1995) TOAD-64, a gene expressed early in neuronal differentiation in the rat, is related to $u n c-33$, a C. elegans gene involved in axon outgrowth. J Neurosci 15:6757-6766.

Nishimura T, Fukata Y, Kato K, Yamaguchi T, Matsuura Y, Kamiguchi H, Kaibuchi K (2003) CRMP-2 regulates polarized Numb-mediated endocytosis for axon growth. Nat Cell Biol 5:819-826.

Pasterkamp RJ, Verhaagen J (2001) Emerging roles for semaphorins in neural regeneration. Brain Res Brain Res Rev 35:36-54.

Perluigi M, Fai Poon H, Hensley K, Pierce WM, Klein JB, Calabrese V, De Marco C, Butterfield DA (2005) Proteomic analysis of 4-hydroxy-2nonenal-modified proteins in G93A-SOD1 transgenic mice-a model of familial amyotrophic lateral sclerosis. Free Radic Biol Med 38:960-968.

Przedborski S (2004) Programmed cell death in amyotrophic lateral sclerosis: a mechanism of pathogenic and therapeutic importance. Neurologist 10:1-7.

Pun S, Santos AF, Saxena S, Xu L, Caroni P (2006) Selective vulnerability and pruning of phasic motoneuron axons in motoneuron disease alleviated by CNTF. Nat Neurosci 9:408-419.

Quach TT, Duchemin AM, Rogemond V, Aguera M, Honnorat J, Belin MF, Kolattukudy PE (2004) Involvement of collapsin response mediator proteins in the neurite extension induced by neurotrophins in dorsal root ganglion neurons. Mol Cell Neurosci 25:433-443.

Quach TT, Massicotte G, Belin MF, Honnorat J, Glasper ER, Devries AC, Jakeman LB, Baudry M, Duchemin AM, Kolattukudy PE (2008a) CRMP3 is required for hippocampal CA1 dendritic organization and plasticity. FASEB J 22:401-409.

Quach TT, Glasper ER, Devries AC, Honnorat J, Kolattukudy PE, Duchemin AM (2008b) Altered prepulse inhibition in mice with dendrite abnormalities of hippocampal neurons. Mol Psychiatry 13:656-658.

Quinn CC, Chen E, Kinjo TG, Kelly G, Bell AW, Elliott RC, McPherson PS, Hockfield S (2003) TUC-4b, a novel TUC family variant, regulates neurite outgrowth and associates with vesicles in the growth cone. J Neurosci 23:2815-2823.

Raoul C, Henderson CE, Pettmann B (1999) Programmed cell death of embryonic motoneurons triggered through the Fas death receptor. J Cell Biol 147:1049-1062.

Raoul C, Estevez AG, Nishimune H, Cleveland DW, deLapeyriere O, Henderson CE, Haase G, Pettmann B (2002) Motoneuron death triggered by a specific pathway downstream of Fas. potentiation by ALS-linked SOD1 mutations. Neuron 35:1067-1083.

Raoul C, Abbas-Terki T, Bensadoun JC, Guillot S, Haase G, Szulc J, Henderson CE, Aebischer P (2005) Lentiviral-mediated silencing of SOD1 through RNA interference retards disease onset and progression in a mouse model of ALS. Nat Med 11:423-428.

Raoul C, Barker SD, Aebischer P (2006a) Viral-based modelling and correction of neurodegenerative diseases by RNA interference. Gene Ther 13:487-495.

Raoul C, Buhler E, Sadeghi C, Jacquier A, Aebischer P, Pettmann B, Henderson $\mathrm{CE}$, Haase G (2006b) Chronic activation in presymptomatic amyotrophic lateral sclerosis (ALS) mice of a feedback loop involving Fas, Daxx, and FasL. Proc Natl Acad Sci U S A 103:6007-6012.

Rogemond V, Auger C, Giraudon P, Becchi M, Auvergnon N, Belin MF, Honnorat J, Moradi-Ameli M (2008) Processing and nuclear localization of CRMP2 during brain development induce neurite outgrowth inhibition. J Biol Chem 283:14751-14761.

Royo NC, Vandenberghe LH, Ma JY, Hauspurg A, Yu L, Maronski M, Johnston J, Dichter MA, Wilson JM, Watson DJ (2008) Specific AAV serotypes stably transduce primary hippocampal and cortical cultures with high efficiency and low toxicity. Brain Res 1190:15-22.

Saxena S, Cabuy E, Caroni P (2009) A role for motoneuron subtypeselective ER stress in disease manifestations of FALS mice. Nat Neurosci 12:627-636.

Schaefer AM, Sanes JR, Lichtman JW (2005) A compensatory subpopulation of motor neurons in a mouse model of amyotrophic lateral sclerosis. J Comp Neurol 490:209-219.

Su KY, Chien WL, Fu WM, Yu IS, Huang HP, Huang PH, Lin SR, Shih JY, Lin YL, Hsueh YP, Yang PC, Lin SW (2007) Mice deficient in collapsin response mediator protein-1 exhibit impaired long-term potentiation and impaired spatial learning and memory. J Neurosci 27:2513-2524.

Suzuki Y, Nakagomi S, Namikawa K, Kiryu-Seo S, Inagaki N, Kaibuchi K, 
Aizawa H, Kikuchi K, Kiyama H (2003) Collapsin response mediator protein-2 accelerates axon regeneration of nerve-injured motor neurons of rat. J Neurochem 86:1042-1050.

Towne C, Raoul C, Schneider BL, Aebischer P (2008) Systemic AAV6 delivery mediating RNA interference against SOD1: neuromuscular transduction does not alter disease progression in fALS mice. Mol Ther 16: 1018-1025.

Turner BJ, Talbot K (2008) Transgenics, toxicity and therapeutics in rodent models of mutant SOD1-mediated familial ALS. Prog Neurobiol 85:94-134.

van Zundert B, Peuscher MH, Hynynen M, Chen A, Neve RL, Brown RH Jr, Constantine-Paton M, Bellingham MC (2008) Neonatal neuronal cir- cuitry shows hyperexcitable disturbance in a mouse model of the adultonset neurodegenerative disease amyotrophic lateral sclerosis. J Neurosci 28:10864-10874.

Wengenack TM, Holasek SS, Montano CM, Gregor D, Curran GL, Poduslo JF (2004) Activation of programmed cell death markers in ventral horn motor neurons during early presymptomatic stages of amyotrophic lateral sclerosis in a transgenic mouse model. Brain Res 1027:73-86.

Wong PC, Borchelt DR (1995) Motor neuron disease caused by mutations in superoxide dismutase 1. Curr Opin Neurol 8:294-301.

Yoshida H, Watanabe A, Ihara Y (1998) Collapsin response mediator protein-2 is associated with neurofibrillary tangles in Alzheimer's disease. J Biol Chem 273:9761-9768. 